\title{
Evaluation of step's slope on energy dissipation in stepped spillway
}

\author{
Ali Heidari ${ }^{1}$, Poria Ghassemi ${ }^{2}$ * \\ ${ }^{1}$ PhD, Civil Engineering, Shahrekord University, Iran \\ ${ }^{2} \mathrm{MSc}$, Civil Engineering, Shahrekord University, Iran \\ *Corresponding author E-mail: poria.gh_fxprice@yahoo.com
}

Copyright $($ C) 2014 Poria Ghassemi, Ali Heidari. This is an open access article distributed under the Creative Commons Attribution License, which permits unrestricted use, distribution, and reproduction in any medium, provided the original work is properly cited.

\begin{abstract}
Stepped spillways are kind of dissipative structures used in rivers with steep slopes to reduce the flow energy and also the scouring potential of water. This dissipation is caused through diffusion along the spillway. The reduction of energy also leads to optimize the still basin geometry and performance downstream, and thus make the project more economic. In this paper, the hydraulic behaviour of stepped spillway is investigated based on kinetic energy. The results show that the average mean kinetic energy decreases upon an appraise in steps's slope. Finally, horizontal steps are proposed.
\end{abstract}

Keywords: Stepped Spillway, Mean Kinetic Energy, Dissipation, and Steps's Slope.

\section{Introduction}

A spillway is a hydraulic structure that is provided at storage and detention dams to release surplus or flood water that cannot be safely stored in the reservoir. When the reservoir's storage capacity is exceeded, water flows over the spillway crest and accelerates down the chute creating high velocities at the toe. This may cause dangerous scour in the natural channel below the hydraulic structure. As a remedy, various forms of energy dissipation mechanisms have been used in practice: simple aprons, stilling basins, straight drops, impact basins, baffled chutes, and plunge pools. Although these methods have proven to be effective in dissipating energy, they incur a substantial increase in the cost of construction of the dam. They may also develop defects that affect the structural integrity of the spillway and may cause failure of the dam [1].

One possible solution is to use a stepped ogee-profile spillway instead of the traditional smooth ogee-profile spillway, where a series of drops are introduced in the invert from the vicinity of the crest to the toe. The stepped spillway is expected to generate substantial energy losses over a wide range of operating flow heads with the steps acting as roughness elements that reduce the flow terminal velocities. In recent years stepped spillways have become popular due to the low-cost and relatively high-speed in construction and rehabilitation of dams using the method of roller compacted concrete [2].

Efficient and safe design procedures for spillways can only be achieved through a comprehensive understanding of the intricacies of the flow. Historically, engineers and scientist have resorted to investigating the flow through laboratory experimentation on scaled down models of spillways [2].

\section{Literature review}

The literature surveyed by the researchers yielded numerous and wide ranging references on laboratory experimentation using scaled down spillways. In contrast, only a few references on computational modeling were found. The recent and relevant references that dealt with laboratory investigations addressed the main characteristics of the flow that influence the design of a stepped spillway. This included scale effects, transition from nappe flow to skimming flow, inception of air entrainment, air concentrations, velocity distributions, pressure distributions, and energy dissipation. As a result, semi-empirical equations have been developed to aid in the design of actual spillways and to lessen the need for individual experimental model studies [3]. 
The ancestry of modern CFD methods can be traced back to two well established and widely used computational methods: finite difference and finite element. The finite volume method, which has been extensively used to model a wide range of fluid-flow problems, was originally developed as a special finite difference formulation. The volume-offluid (VOF) method is an interface tracking scheme that has been used to model free surfaces. All the aforementioned methods have been applied to model flow over a spillway [4].

It is clear that there has been renewed interest in the use of stepped spillways in hydraulic engineering (as evidenced by the numerous experimental works on scale down models). However, there has been little progress in the computational modeling of such structures [5].

\section{Modeling procedure}

In order to evaluate the influence of step's slope on energy dissipation, various models are modeled in Flow3D. The negative slopes include zero, 15, 30 and 40 degrees. The spillway has 28 meters height, 60 meters length and 5 meters width. The inflow rate is assumed to be $25 \mathrm{~m}^{3} / \mathrm{s}$. To appraise the efficiency, the mesh size is considered 0.2 meter.

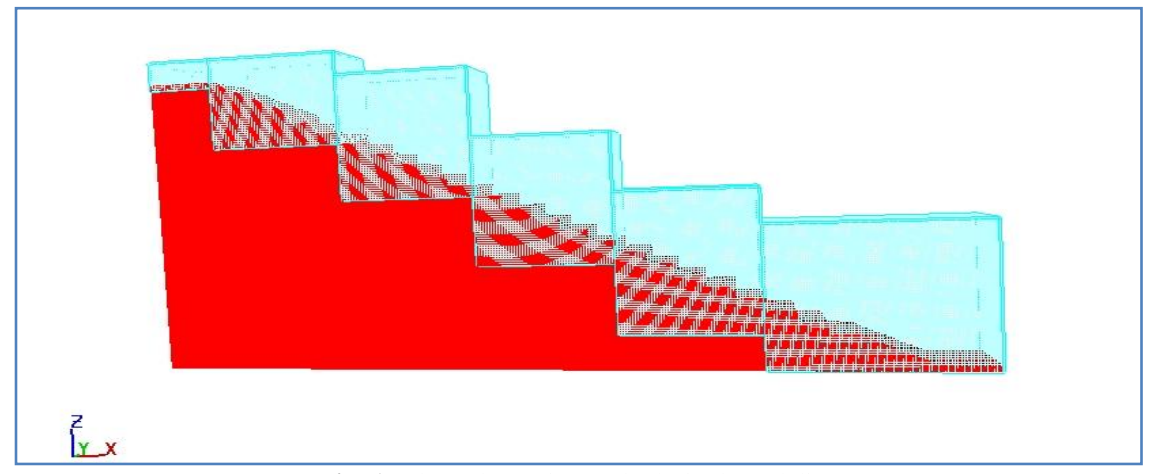

Fig. 1: The Schematic Meshed Final Modeling

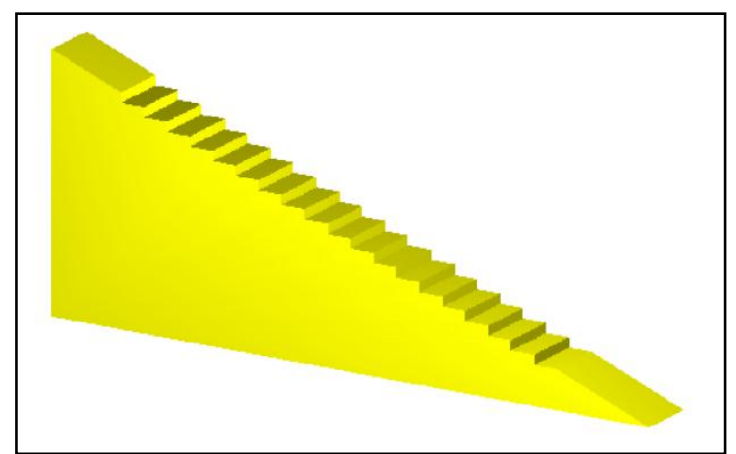

Fig. 2: The Schematic Model for Zero Degree Model

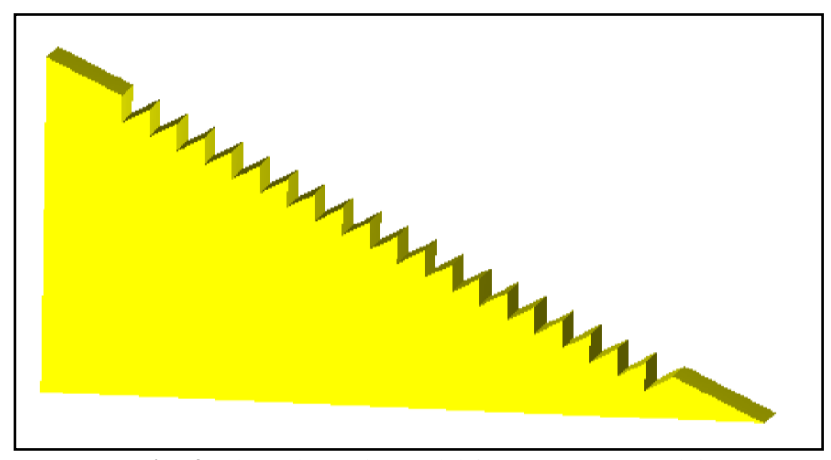

Fig. 4: The Schematic Model for 30 Degree Model

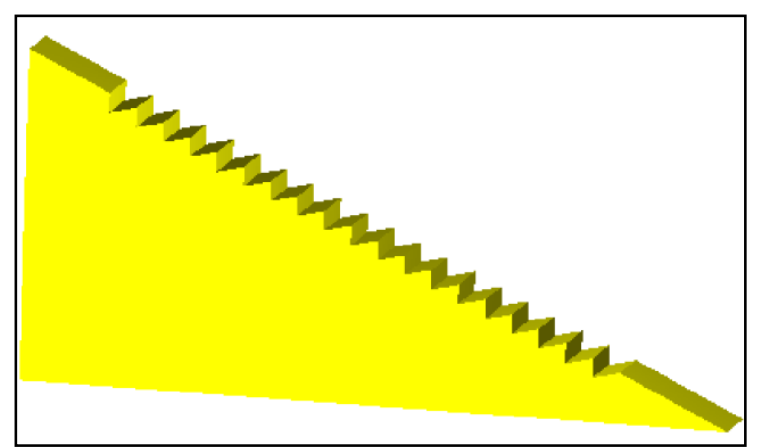

Fig. 3: The Schematic Model for 15 Degree Model

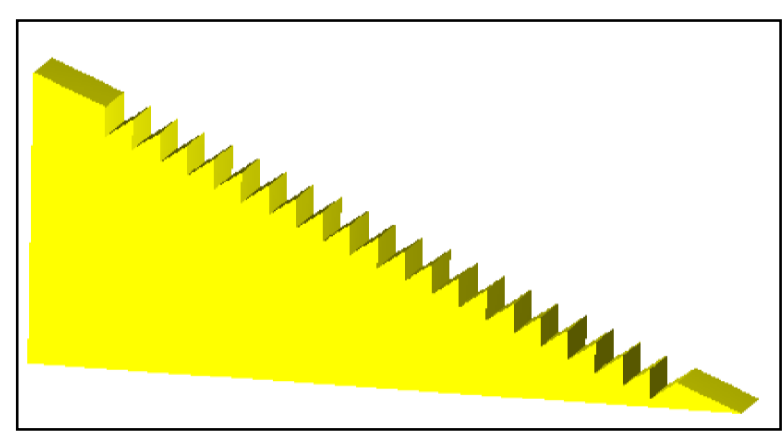

Fig. 5: The Schematic Model for 40 Degree Model

\section{Results}

As mentioned before, the results are illustrated for various slopes. The scope of this research is to investigate the effect of step's slope on mean kinetic energy (mke). 
In the below figure, mean kinetic energy for zero degree model is presented. The final mean kinematic energy for this case equals to $70.2 \mathrm{~J} / \mathrm{kg}$.

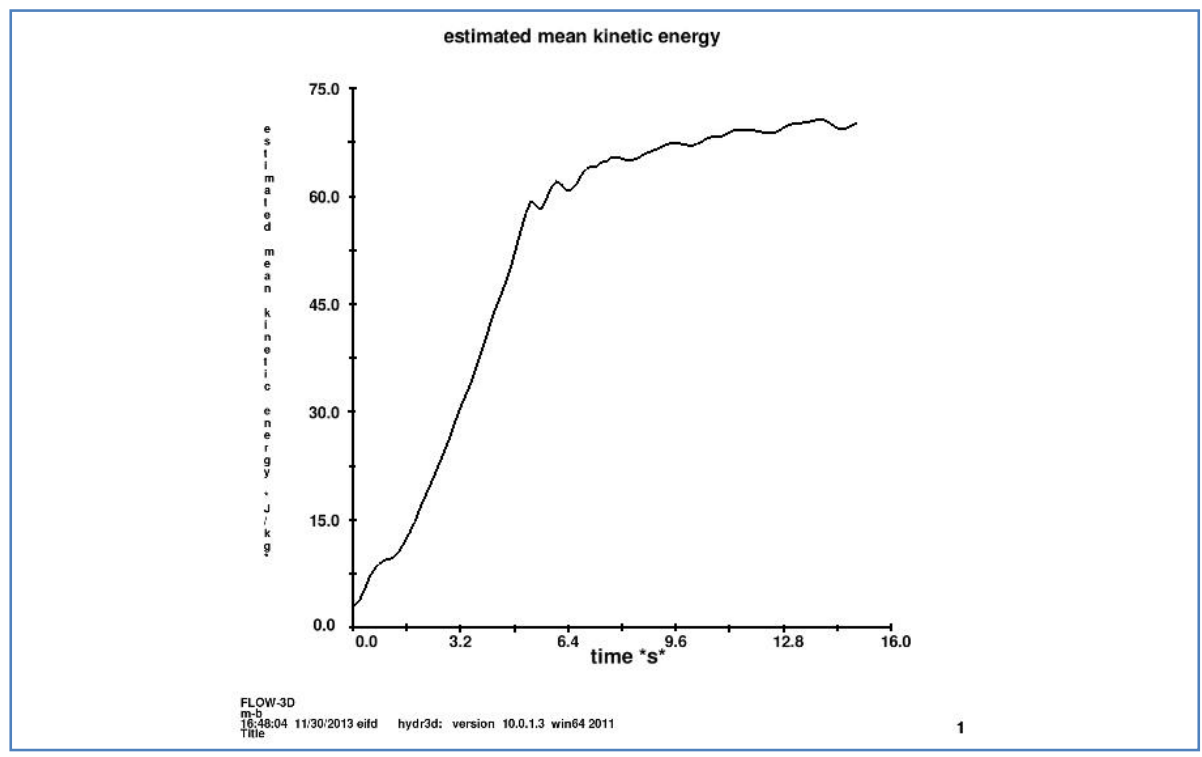

Fig. 6: Mean Kinetic Energy for Zero Degree Model

In the below figure, mean kinetic energy for 15 degree model is presented. The final mean kinematic energy for this case equals to $55.9 \mathrm{~J} / \mathrm{kg}$.

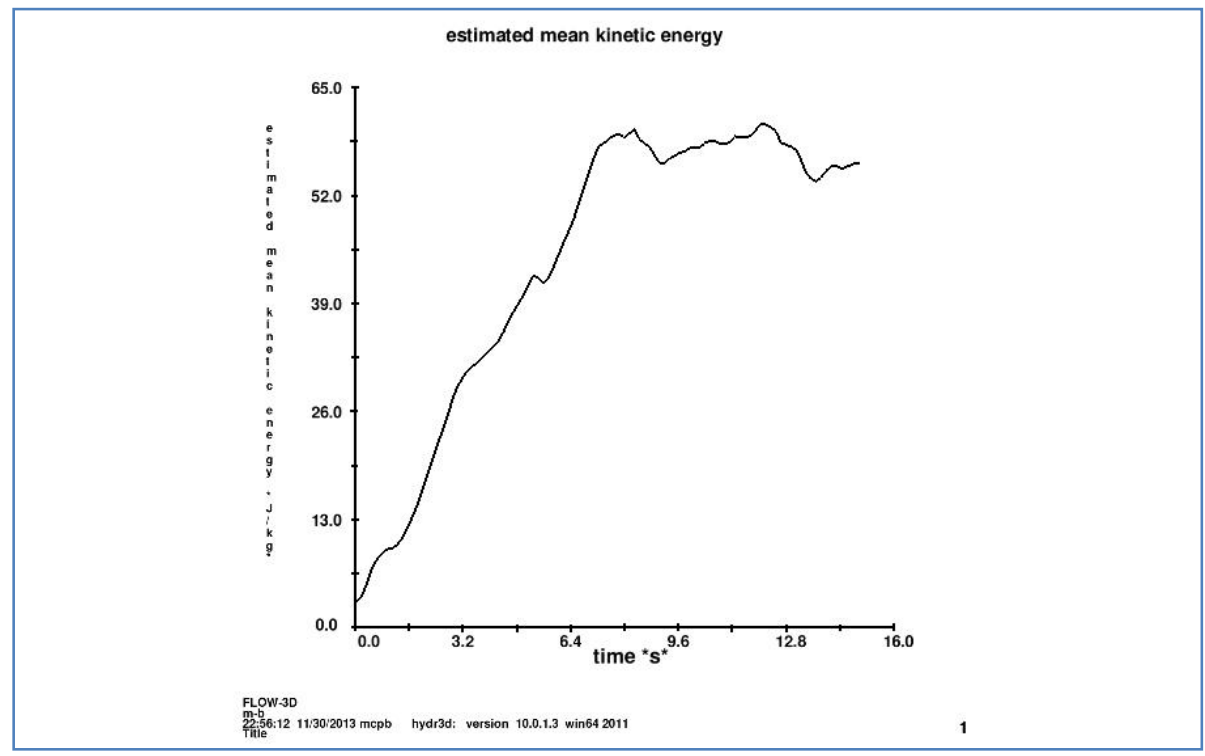

Fig. 7: Mean Kinetic Energy for 15 Degree Model

In the below figure, mean kinetic energy for 30 degree model is presented. The final mean kinematic energy for this case equals to $32 \mathrm{~J} / \mathrm{kg}$. 


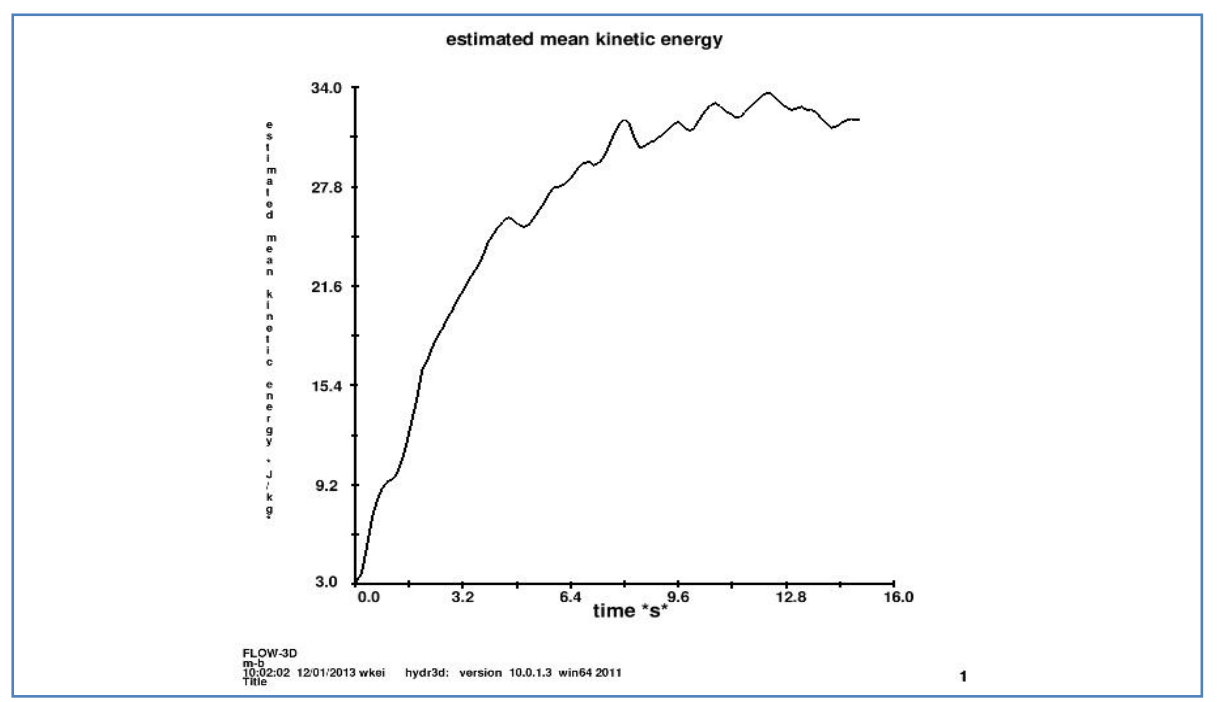

Fig. 8: Mean Kinetic Energy for 30 Degree Model

In the below figure, mean kinetic energy for 40 degree model is presented. The final mean kinematic energy for this case equals to $20.3 \mathrm{~J} / \mathrm{kg}$.

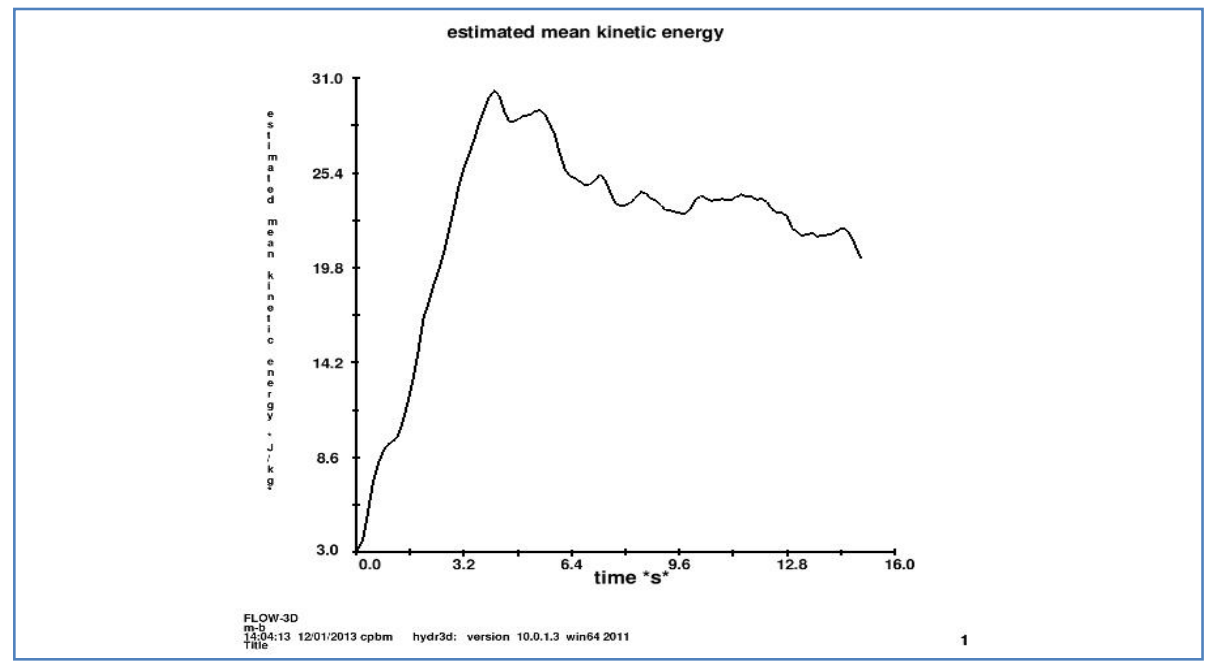

Fig. 9: Mean Kinetic Energy for 40 Degree Model

In the following graph, the total results for all models are illustrated.

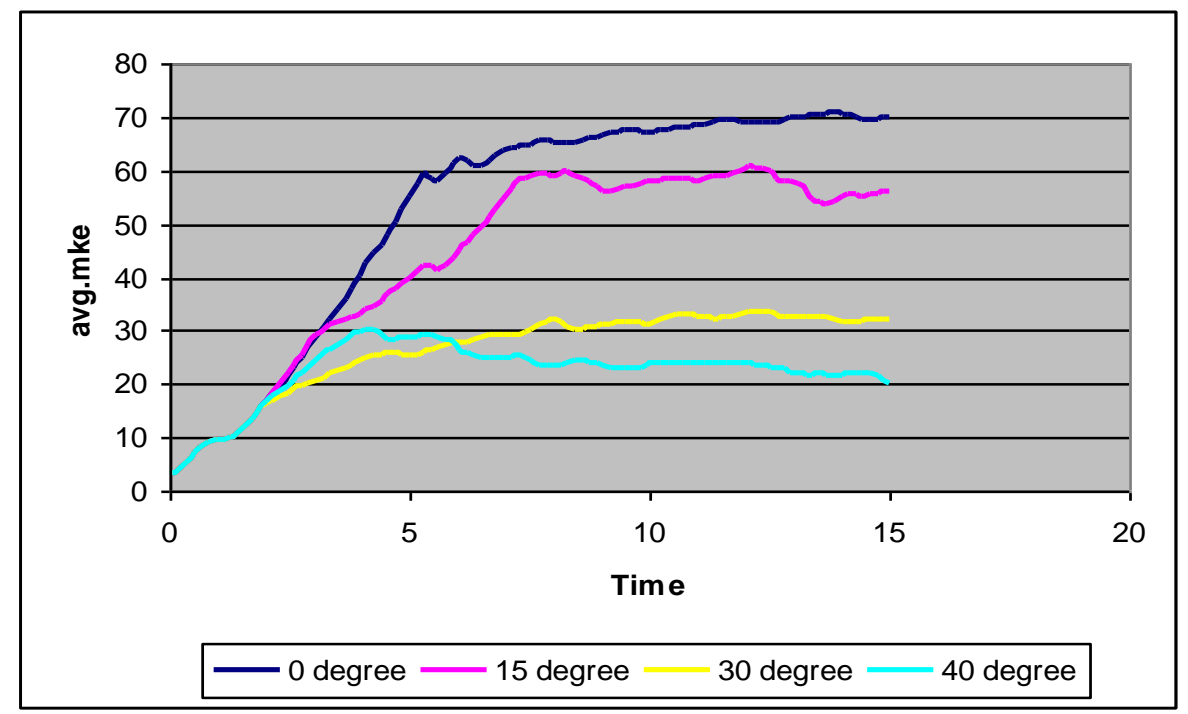

Fig. 10: Comparison of Mke for Various Stepped Spillways 
Based on the graph it is observed that based on mke parameter, the best performance is for zero degree stepped spillway. The next optimized values are for 15, 30 and 40 degree respectively. So, it is concluded that the mke parameter decreases as the steps degree increases.

In the condition of zero degree, the mke is $20 \%$ more than $15^{\circ}$ models, $54 \%$ more than $30^{\circ}$ and finally $71 \%$ more than $40^{\circ}$ models.

The mentioned values are presented in the below figure.

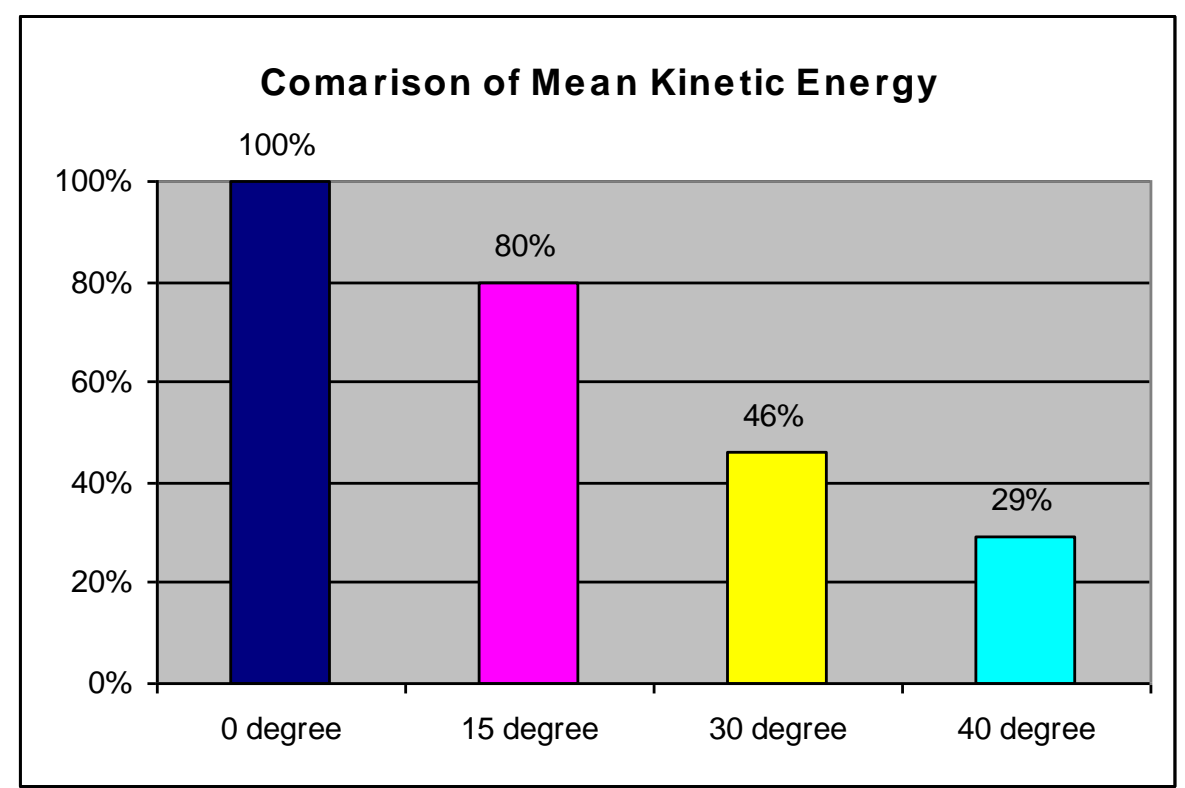

Fig. 11: Comparison of Mke Efficiency for Various Slopes of Models

\section{Conclusion}

Based on various models performed on Flow3D about investigation of the influence of step's slope on mean kinetic energy in stepped spillways, it is concluded that, the best performance is for zero degree stepped spillway. The next optimized values are for 15, 30 and 40 degree respectively. So, it is concluded that the mke parameter decreases as the steps degree increases. Finally, in the condition of zero degree, the mke is $20 \%$ more than $15^{0}$ models, $54 \%$ more than $30^{\circ}$ and finally $71 \%$ more than $40^{\circ}$ models.

\section{References}

[1] Roshan, R., Azamathulla, H. Md., Marosi, M., Sarkardeh, H., Pahlavan, H., Ab Ghani, A., (2010), "Hydraulics of stepped spillways with different numbers of steps". Journal of Dams and Reservoirs, Vol. 20, No.3, pp 131-136 http://dx.doi.org/10.1680/dare.2010.20.3.131.

[2] Dermawan, V., Anwar, N., Edijanto, (2010), "Hydraulic model of Flow Conditions on Stepped Spillways due to number of Steps". International Journal of Academic Research, Vol. 2, No. 5, pp. 775-784.

[3] Chafi. C., Hazzab. A., Seddini. A. (2010) "Study of Flow and Energy Dissipation in Stepped Spillways" Jordan Journal of Civil Engineering, Volume 4.

[4] Aras.E, Berkun.M (2010) "spillway effects on stream reaeration" Gumushane University, Department of Civil Engineering, Gumushane 29100, Turkey, Karadeniz Technical University, Department of Civil Engineering, Trabzon 61080, Turkey, Water Research Commission (WRC).

[5] F.A. Bombardelli, I. Meireles, J. Matos, Laboratory measurements and multi-block numerical simulations of the mean flow and turbulence in the non-aerated skimming flow region of steep stepped spillways, Environ. Fluid Mech., 11 (3) (2010), pp. 263-288 http://dx.doi.org/10.1007/s10652-010-9188-6. 